\title{
Prose recall in first-grade children using imagery, pictures, and questions
}

\author{
PETER WOOLDRIDGE, LYNN NALL, LONNIE HUGHES, THYRA RAUCH, \\ GREG STEWART, and CHARLES L. RICHMAN \\ Wake Forest University, Winston-Salem, North Carolina 27109
}

\begin{abstract}
Recent studies suggest that children younger than 8 years old fail to use imagery instructions, resulting in memorial deficits. This inferior recall performance has been ascribed to encoding, storage, and/or retrieval deficiencies. One method recently used to assess the encoding/storage vs. the retrieval effects of imagery instructions on recall is to employ imagery instructions with or without a partial picture during the learning and/or recall phase of the study. The present study employed a 2 (imagery, no-imagery instructions) by 2 (partial picture during story, no partial picture during story) by 2 (partial picture during questioning, no partial picture during questioning) factorial design, with first-grade children as subjects. Recall of items specified in narrative passages was the dependent variable. Recall of narrative prose for 6-year-old children was consistently facilitated by partial pictures during story presentation. Imagery instructions were ineffective in facilitating recall.
\end{abstract}

Child researchers have become increasingly interested in imagery as it relates to cognitive development. Pressley (1977), for example, suggests that the age span of 5-8 years is the crucial period in the development of imagery in cognitive processes. Piaget and Inhelder (1971) suggest that cognitive stages are highly related to the child's ability to manipulate images.

Most of the recent child research has focused on the question of whether young school-age children employ imagery strategies as effectively as older children. Lesgold, Levin, Shimron, and Guttman (1975) and Rohwer (1973) suggest that a lower probability exists in younger children relative to older children in their use of images. Current developmental research tends to support their position. For example, Shimron (1975) found that although recall performance of narrative passages was facilitated by imagery instructions presented to fourth-grade children, imagery instructions failed to aid recall memory of first-graders. Guttman, Levin, and Pressley (1977) were concerned with the possible interactive effects of imagery and visually presented illustrations on the recall of a prose passage. The research paradigm included a control condition in which only the story was read, an imagery instruction condition, a group that was shown a complete picture during the story, and a group that received the story accompanied by partial pictures. These partial pictures contained all the information included in the story except the to-beremembered item. Thus, the object of interest (e.g., a

This research was supported by funds from the National Institute of Mental Health, PHS, 1R01MH36491-01, and the Wake Forest University Research and Publication Fund to Charles L. Richman. Requests for reprints should be sent to Charles L. Richman, Department of Psychology, Wake Forest University, Box 7778, Winston-Salem, North Carolina 27109. turkey on the family table) was hidden from view. Subjects in this condition were told to image the missing object. The results showed that across conditions, children learned best when presented with a complete illustration of the story. In the kindergarten and secondgrade samples, there were no significant recall differences between the imagery, partial picture, and control subjects. Within the third-grade sample, all three experimental groups' recall scores were superior to those of the control subjects. Guttman et al. concluded that they replicated the developmental imagery effect in children's prose learning.

Ruch and Levin (1979) extended the Guttman et al. (1977) study with first-grade children using one additional condition, a partial picture, which was presented during the story and the questioning phases (i.e., reinstated picture condition). The subjects who were shown partial pictures during the story phase of learning did not differ in recall from controls; however, recall was superior to that of controls for subjects who were shown partial pictures during the questioning phase of the study. Ruch and Levin (1979) concluded that the problem for young children is not imagery generation, as suggested by Guttman et al. (1977); rather, it is image retrieval. That is, the presentation of the partial picture during questioning served as a cue for retrieval of generated imagery.

These data suggest that children approximately 6 years of age do not generate internal images unless they are reminded to do so during testing. There is, however, a basic methodological concern with the storage/retrieval conclusions derived from many of the child imagery studies; that is, the effects of all relevant variables (imagery instructions, partial pictures during story and/ or questioning) in combination have not been investi- 
gated. For example, Guttman et al. (1977) did not include a partial picture condition without instructions to image.

Purkel and Bornstein (1980) confounded imagery instructions with the story presentation of partial pictures, and Ruch and Levin's (1977) original study with third-graders confounded imagery instructions with partial pictures. In the Ruch and Levin (1977) study, as in their 1979 study, partial pictures aided retrieval but not storage.

To assess the interactive effects of imagery instructions and partial pictures during story and/or questioning, we used a 2 (imagery instructions, I, vs. no imagery instructions, NI) by 2 (story with partial picture, S+P, vs. story without partial picture, S-P) by 2 (questions with partial picture, $\mathrm{Q}+\mathrm{P}$, vs. questions without partial picture, Q-P) factorial design. Among the more important of these conditions is the one in which children are asked to image, are read a story without pictures, and are then given pictures during questioning. If, as Ruch and Levin (1979) assert, the child is generating images but experiencing difficulty in retrieving them, then Group I/S-P/Q+P's recall performance should not be different from that of the group receiving imagery instructions, story with pictures, and questions with pictures (Group I/S+P/Q+P).

There are a number of possible outcomes that would suggest the efficacy of imagery instructions: (1) If imagery instructions relative to no imagery instructions facilitate recall when the partial picture is present during the story presentation and questioning phases, then one might conclude that imagery aids both the encoding/ storage and retrieval aspects of memory. (2) If imagery instructions relative to no imagery instructions facilitate recall when and only when the partial picture is presented during the story phase, then a reasonable conclusion would be that imagery facilitates encoding/storage. (3) If imagery instructions relative to no imagery instructions facilitate recall only when the partial picture is presented during the questioning phase, then one might assume that imagery facilitates retrieval. (4) If imagery instructions fail to facilitate recall regardless of conditions, we would conclude that young school-age children do not make effective use of imagery in learning and/or memory. (5) A fifth possibility remains. If imagery instructions relative to no imagery instructions result in inferior recall when the pictures are presented during the story and/or the questioning phase, we would consider that subject-generated images are in conflict with propositional statements that are represented in the story and/ or the child's perceptions of the partial picture. In any event, deficit recall as a function of imagery instructions would suggest that the young child is generating images but those images are in competition with the images generated by the story and/or the partial pictures. A number of processes may be intimately involved in imageryinstructed recall (e.g., attentional, organizational, etc.).

\section{METHOD}

\section{Subjects}

Forty male and 40 female 6-year-old children were subjects (mean age $=6$ years 7 months). Children were randomly assigned to one of eight experimental conditions. The first-grade children were obtained from three public elementary schools. Approximately equal numbers of black and white male and female children were proportionally assigned to subgroups.

\section{Materials}

Two 10 -sentence narrative paragraphs were developed. A thematically related picture (8.5 $\times 11$ in.) accompanied each sentence of the narrative. The pictures were partial representations of the sentences, in that each sentence referred to an object not present in the picture. Except for this missing object, the pictures fully represented the details of the sentence.

Key words (i.e., object missing in the picture) in each sentence were counterbalanced for position. Approximately five of the words occurred at the end of the sentence, and approximately five were placed earlier in the sentence. Sentences ranged from 10 to 15 words. Key words were simple one- or twosyllable concrete nouns.

Attempts were made to counterbalance for sex and race of the figures in the pictures. Male and female and black and white figures appeared equal numbers of times.

Two "WH" questions were developed for each story. Each question asked for identification of the item missing from the partial picture. Phrases taken from the sentences were contained in each question. For example, Sentence 1 is "Johnny woke up and put his shoes on one sunny morning." Question 1 would then be "What did Johnny put on when he woke up?"

Prior to the experiment, norming of pictures and sentences was performed on 24 6-year-old children who were not subjects in the experiment. Each child was asked, "Can you guess the answer to this question?" or "Can you guess what is missing from this picture?" Sentences and key words were used in the actual study if less than $10 \%$ of the norming group guessed the correct response.

\section{Design}

Eight experimental conditions were used: groups with or without imagery instructions (I and NI), partial picture presented or not presented during the story (S+P or S-P), and/or partial pictures presented or not presented during questioning $(\mathrm{Q}+\mathrm{P}$ or Q-P). For example, a group receiving imagery instructions, story with partial picture, and questioning with partial picture is designated Group I/S+P/Q+P.

Children in each group were randomly assigned to one of the eight experimental conditions, yielding a total of 10 children/cell. Sex of the experimenter was counterbalanced; that is, half the girls (boys) were tested by female (male) experimenters. Half the children in each group were presented Story 1 prior to Story 2, and the remaining children were presented Story 2 prior to Story 1. The two stories and questions used were as follows.

Story 1: "Johnny woke up and put on his shoes one sunny morning. Mother was downstairs cooking oatmeal for breakfast. After breakfast, Johnny went outside and watched a butterfly. Just then his friend Mary rode by wearing her new hat. Later that afternoon, Johnny typed a letter to his grandma and put it in the envelope. He told her about his friend Mark, who bought a blanket for his new puppy. He also told her that Mark's dog hurt his foot and that the doctor put a cast on it. Johnny looked out of the window and saw the mailman put the letter in his truck. Then Johnny went down to the drugstore for ice cream with nuts on top. Soon, it was nighttime, and when the stars came out, Johnny knew it was time for bed." Questions: "What did Johnny put on when he woke up? What was mother cooking for breakfast? What did Johnny watch after breakfast? What was 
Mary wearing when she rode by? What did Johnny do with the letter to his grandma? What did Mark buy for his puppy? What did the doctor put on the puppy's foot? Where did the mailman put Johnny's letter? What did Johnny have on top of his ice cream? What made Johnny know it was time for bed?"

Story 2: "Daddy and Suzy went to the store to buy seeds and a shovel. Daddy and Joey put sticks in the ground for the seeds. Daddy drove the tractor while Suzy planted carrots. While Suzy worked Joey and Marcia played with the wheelbarrow and wagon. Suzy dressed a scarecrow to scare away rabbits. Later Suzy and her baby doll watched the rain. The next day Daddy and Joey dug the garden to keep the weeds out of the garden. Mark and Marcia picked cherries. Suzy sold her flowers at the market. Mommy used the fruit to make a pie." Questions: "What did Daddy and Suzy buy at the store? What did Daddy and Joey put in the ground for the seeds? What did Suzy plant? What did Joey and Marcia play with? What did Suzy want to scare away with the scarecrow? Who watched the rain with Suzy? What did Daddy and Joey want to keep out of the garden? What did Joey and Marcia pick? What did Suzy sell at the market? What did Mommy make with the fruit?"

\section{Procedure}

Each child was individually tested in her/his school. The child was taken by the experimenter from her/his classroom to a quiet room for testing. All subjects received the following instructions: "I am going to tell you a story. Listen carefully and try to remember everything you can about the story. I am going to ask you some questions about the story when we are through." The following instructions were given, depending on the experimental condition. (1) Groups $\mathrm{I} / \mathrm{S}+\mathrm{P} / \mathrm{Q}+\mathrm{P}$ and $\mathrm{NI} / \mathrm{S}+\mathrm{P} / \mathrm{Q}+\mathrm{P}$ : "I am going to read you the [first/second] story and show you some pictures that go with the story. Listen carefully because afterward I will ask you some questions." (story) "Let's look at the pictures again while I ask you some questions." (questions) (2) Groups $\mathrm{I} / \mathrm{S}-\mathrm{P} / \mathrm{Q}+\mathrm{P}$ and NI/S-P/Q+P: "I am going to read you the [first/ second] story. Listen carefully because afterward I will ask you some questions." (story) "Let's look at pictures about the story while I ask you some questions." (questions) (3) Groups I/S+P/ Q-P and NI/S+P/Q-P: "I am going to read you the [first/second] story and show you some pictures that go with the story. Listen carefully because afterward I will ask you some questions about the story." (story) "Now I am going to ask you some questions about the story." (questions) (4) Groups I/S-P/Q-P and NI/S-P/ Q-P: "I am going to read you the [first/second] story. Listen carefully because afterward I will ask you some questions." (story) "Now I am going to ask you some questions about the story." (questions)

Subjects in the imagery instruction groups were instructed to make up a picture of the story and the objects in their head. Prior to the experiment proper, all imagery subjects were first tested for imagery. If the child was not able to image, she/he was trained in a procedure used by Pressley (1976). Subjects were presented a sentence orally and then told to "make up a picture of the sentence in your head." They were then shown a picture depicting the sentence and asked if it resembled their image. If the child said "yes," she/he was tested. If the child said "no," she/he found out her/his image was different from the picture and was corrected.

\section{RESULTS AND DISCUSSION}

The present study was designed to investigate the effects of imagery instructions on storage and retrieval processes in 6-year-old children. Storage and/or retrieval deficits were assessed via the introduction of contextual cues (i.e., partial pictures) during the story presentation and/or the questioning phases of the study.

Contrary to the theoretical position that pictures do not facilitate learning and memory (recall) in young chil- dren (e.g., Samuels, 1970), the present results firmly establish the advantages of partial pictures in facilitating narrative passage memory in children as young as 6 years of age.

There were 20 words to be remembered; each child was given one point for each word correctly recalled. Thus, a maximum of 20 points was possible. A 2 (sex of subject) by 2 (imagery instructions) by 2 (picture presentation in story) by 2 (picture presentation in questioning) analysis of variance was performed on the correct recall scores. One main effect was statistically significant. Recall performance with the partial picture present during the story presentation was superior to conditions without partial pictures $[F(1,64)=10.10, p<.01]$. Table 1 presents the mean percent correct recall for the three primary conditions of the study and sex of subject. Observation of Table 1 shows that the overall effects of imagery instructions, partial picture in questioning, and sex of subject were negligible.

If one considers Group NI/S-P/Q-P as the "control group" with a percent recall score of $48.0 \%$, it is evident that recall was facilitated by the presence of partial pictures during story presentation and verified by comparisons performed between the control group and each of the S+P groups via Duncan's multiple-range tests (ps $<$ $.05)$. The percent correct recall score for the groups when the story did not have an accompanying partial picture (mean percent correct recall $=43.0 \%$ ) was quite similar to the control group ( $p>.05)$. Furthermore, the overall effect of imagery and partial pictures during questioning was minimal when compared to the controlgroup percent recall score. In summary, when comparing the control subjects' recall performance with the percent correct responses of subjects receiving partial pictures during story, the latter had a decided advantage over the former. These findings suggest that first-grade children's memory deficits are due, in part, to the generative/storage phase of information processing, which confirms a recent report by Chechile, Richman, Topinka, and Ehrensbeck (1981).

It is important to note in the present study that imagery instructions failed to facilitate memory, regardless of the presence or absence of partial pictures. This finding provides empirical support for the notion that 6-year-old children do not benefit from imagery instructions (e.g., Lesgold et al., 1975). Dunham and Levin (1979) suggest that a promising way to improve young children's prose learning is to instruct or train them to use

Table 1

Mean Percent Recall as a Function of Sex of Subjects, Imagery Instructions, and Partial Pictures in Story and in Questioning

\begin{tabular}{|c|c|c|c|c|c|c|c|}
\hline \multirow{2}{*}{\multicolumn{2}{|c|}{ Sex of Subject }} & \multirow{2}{*}{\multicolumn{2}{|c|}{ Instructions }} & \multicolumn{4}{|c|}{ Partial Pictures } \\
\hline & & & & \multicolumn{2}{|c|}{ Story } & \multicolumn{2}{|c|}{ Questioning } \\
\hline M & $\mathrm{F}$ & I & $\mathrm{NI}$ & $\mathbf{P}$ & A & $\mathbf{P}$ & A \\
\hline 53 & 54 & 54 & 53 & 60 & 47 & 53 & 54 \\
\hline
\end{tabular}

Note $-M=$ male, $F=$ female $I=$ imagery, $N I=$ no imagery; $P=$ present, $A=$ absent. 
Table 2

Mean Percent Recall as a Function of Sex of Subject by the Presence/Absence of Partial Pictures During Study and/or Questioning for Imagery-Instructed Children

\begin{tabular}{llccc}
\hline & & Boys & Girls & Mean \\
\hline Partial Pictures, Story, and Questioning & I/S+P/Q+P & 57 & 67 & 62 \\
Partial Pictures and Story Only & I/S+P/Q-P & 57 & 44 & 50.5 \\
Partial Pictures and Questioning Only & I/S-P/Q+P & 55 & 46 & 50.5 \\
No Partial Pictures & I/SP/Q+P & 54 & 50 & 52 \\
\hline
\end{tabular}

visual imagery while processing a passage. As in the present study, however, Dunham and Levin (1979) failed to find a facilitatory effect of imagery instructions without partial pictures in the performance of 6-year-old children.

A theoretical consideration in the present study was to assess the validity of the retrieval inefficiency hypothesis (e.g., Ruch \& Levin, 1979). One prediction generated from Ruch and Levin's model is a Picture During Story by Picture During Questioning interaction, with the picture accompanying presentation and questioning superior to all other conditions. In the present study, the thirdorder effect among sex of subject, imagery instructions, pictures in story, and pictures in questioning was marginally significant $[F(1,64)=4.00, p<.05]$, with no other interaction approaching statistical significance (ps>.10). A direct comparison between Ruch and Levin (1979) and the present study is possible if one considers the imageryinstructed groups' recall performance with and without partial pictures. Ruch and Levin (1979) found that subjects who were provided with partial pictures during story and questioning were superior in recall to those children who were not provided with partial pictures and those who were provided only with partial pictures during story presentation. The last two groups' recall scores were virtually identical. The results of the present study confirm Ruch and Levin's (1979) findings.

Table 2 shows that the recall performance of subjects in the picture during story and questioning groups $(\mathrm{I} / \mathrm{S}+\mathrm{P} / \mathrm{Q}+\mathrm{P})$ was superior to that of children in the partial picture during story $(\mathrm{I} / \mathrm{S}+\mathrm{P} / \mathrm{Q}-\mathrm{P})$ and the no partial picture groups (I/S-P/Q-P) $(\mathrm{ps}<.05)$. The latter two groups did not differ $(p>.05)$. There is, however, an interesting footnote to these findings. It is evident from Table 2 that the retrieval inefficiency hypothesis is solely a function of the data derived from first-grade girls. The mean percent correct recall scores for boys in the groups in question were quite similar, whereas the girls' performance in Group $\mathrm{I} / \mathrm{S}+\mathrm{P} / \mathrm{Q}+\mathrm{P}$ was superior to that of the girls in Groups $\mathrm{I} / \mathrm{S}+\mathrm{P} / \mathrm{Q}-\mathrm{P}$ and $\mathrm{I} / \mathrm{S}-\mathrm{P} / \mathrm{Q}-\mathrm{P}$ (ps <.05). Table 2 shows that boys' recall performance was equivalent under each of the three partial picture conditions. Furthermore, girls' recall performance was poor in both of the one-cue conditions (i.e., Groups I/S+P/Q-P and $\mathrm{I} / \mathrm{S}-\mathrm{P} / \mathrm{Q}+\mathrm{P})$. In summary, the present study supports Ruch and Levin's (1979) retrieval inefficiency hypothesis with first-grade girls. Unfortunately, a direct comparison between the present results and Ruch and Levin's (1979) is impossible, since they did not enter sex of subject in their analyses. Furthermore, we had no a priori predictions regarding an interaction between sex of subject and partial picture/imagery test procedures and are, therefore, reluctant to impart meaning to this finding.

\section{REFERENCES}

Chechile, R. A., Richman, C. L., Topinka, C., \& Ehrensbeck, K. A developmental study of storage and retrieval of information. Child Development, 1981, 52, 251-259.

Dunham, T. C., \& Levin, J. R. Imagery instructions and young children's prose learning: No evidence of support. Contemporary Educational Psychology, 1979, 42, 107-113.

Guttman, J., Levin, J. R., \& Pressley, M. Pictures, partial pictures, and young children's oral prose learning. Journal of Educational Psychology, 1977, 69, 473-480.

Lesgold, A. J., Levin, J. R., Shimron, J., \& Guttman, J. Pictures and young children's learning from oral prose. Journal of Educational Psychology, 1975, 67, 636-642.

Piaget, J., \& Inhelder, B. Mental imagery in the child. New York: Basic Books, 1971.

Pressley, M. Mental imagery helps eight-year-olds remember what they read. Journal of Educational Psychology, 1976, 68, 355-359.

Pressley, M. Imagery and children's learning: Putting the picture in developmental perspective. Review of Educational Research, 1977, 47, 585-622.

Purkel, W., \& Bornstein, M. H. Pictures and imagery both enhance children's short-term and long-term recall. Developmental Psychology, 1980, 16, 153-154.

ROHWER, W. D., JR. Elaboration in childhood and adolescence. In $\mathrm{M}$. W. Reese (Ed.), Advances in child development and behavior (Vol. 8). New York: Academic Press, 1973.

Ruch, M. D., \& Levin, J. R. Pictorial organization versus verbal repetition of children's prose: Evidence for processing differences. A V Communication Review, 1977, 25, 269-280.

Ruch, M. D., \& Levin, J. R. Partial pictures as imagery-retrieval cues in young children's prose recall. Journal of Experimental Child Psychology, 1979, 28, 268-279.

Samuels, S. J. Effects of pictures on learning to read, comprehension, and attitudes. Review of Educational Research, 1970, 40, 397-407.

Shimron, J. Imagery and comprehension of prose by elementary school children. (Doctoral dissertation, University of Pittsburgh, 1974.) Dissertation Abstracts International, 1975, 36, 795-A. (University Microfilms No. 75-18, 254)

(Received for publication August 6, 1982.) 